\title{
ORF3 as a sensitive and specific diagnostic index for hepatitis $E$
}

\author{
LIJUAN LI, MIN LIU, CHENGRUI GENG, YUNMEI ZOU and TONG JIAO \\ School of Public Health, Dali University, Dali, Yunnan 671000, P.R. China
}

Received August 30, 2016; Accepted March 3, 2017

DOI: $10.3892 / e t m .2017 .4337$

\begin{abstract}
We explored the significance of the expression of hepatitis E virus (HEV) open reading frame 3 (ORF3) in hepatitis $\mathrm{E}$ rat models. We also investigated its diagnostic value. Forty Sprague-Dawley (SD) rats were infected with HEV and 10 uninfected rats were selected for the control group. Rats were sacrificed at 14, 21, 35 and 70 days after infection. They were divided into 4 groups: Model group 1, model group 2, model group 3 and model group 4. ORF3 protein expression level in liver tissue, level of adipokines [fatty acid synthase (FAS), tissue inhibitor of metalloproteinase-2 (TIMP-2) and angiotensin-converting enzyme inhibitor 2 (ACE-2)], Th1/Th2 cells balance [interferon (IFN), interleukin-4 (IL-4) and Th1/Th2] and the level of immune outcome (levels of $\mathrm{CD}^{+}, \mathrm{CD}^{+}$ $\mathrm{T}$ lymphocytes and $\mathrm{CD} 4^{+} / \mathrm{CD} 8^{+}$) were measured and compared among groups. Our results showed that $\mathrm{HEV} \mathrm{IgG} \mathrm{and}$ HEV RNA levels in the model group 3 were higher than those in the other 3 groups. Compared with the control group, expression level of ORF3 protein in the liver tissue as well as Fas and TIMP levels were significantly higher in the model group 3. ACE-2 level was significantly lower than that of the control group $(\mathrm{P}<0.05)$. In the model group $3, \mathrm{IFN}-\gamma, \mathrm{IL}-4$ and Th1/Th2 levels were meaningfully higher than those of the control group. $\mathrm{CD}^{+} \mathrm{T}$ lymphocytes and $\mathrm{CD} 4^{+} / \mathrm{CD}^{+}$ratio were obviously lower than those in the control group $(\mathrm{P}<0.05)$. The expression level of ORF3 was positively correlated with levels of Fas, TIMP-2 and Th1/Th2. It was negatively correlated with ACE- 2 and $\mathrm{CD}^{+} / \mathrm{CD}^{+}$levels $(\mathrm{P}<0.05)$. We concluded that ORF3 expression level was directly related to severity and prognosis, and that ORF3 protein can be considered as a sensitive and specific diagnostic index.
\end{abstract}

\section{Introduction}

Hepatitis E virus (HEV), a single-stranded, positive-sense RNA virus, is responsible for hepatitis E. HEV genome contains three open reading frames (ORFs). ORF1 encodes the

Correspondence to: Professor Lijuan Li, School of Public Health, Dali University, 1 Xueren Road, Dali, Yunnan 671000, P.R. China E-mail:1i_lijuan9@163.com

Key words: hepatitis E, open reading frame 3, adipocytokines, Th1/Th2 nonstructural proteins, ORF2 encodes the capsid protein and ORF3 encodes a small multifunctional protein (1-3). ORF3 protein plays an important role in viral signal transduction and immune suppression, and some believe that ORF3 may even play a role in virus pathogenicity $(2,3)$. ORF3 protein can damage the host cell function and accelerate the release of viral particles from the infected cells (4). In this study, we explored the significance of ORF3 in the progression of the disease. We also investigated its diagnostic value. SD rat models with hepatitis E were established and the expression of ORF3 in liver tissue was studied. The effect of ORF3 on the imbalance of hepatitis E adipokines, inflammatory cytokines and immune function was also investigated.

\section{Materials and methods}

Animal sources. Fifty adult male Sprague-Dawley (SD) rats of SFP grade with gestational age of 3-5 weeks weighing $180 \pm 10 \mathrm{~g}$, were purchased from Shanghai Sangon Animal Experiment Center (Shanghai, China) and fed conventionally. Experiments were conducted when rats adapted to their new environment. Before the experiment, HEV IgG level in serum and liver function indexes were evaluated and results were all negative. This study was approved by the Medical Ethics Committee of Dali University.

Hepatitis E model and experimental grouping. HEV-positive pig feces were purchased from Lanzhou Veterinary Institute of Chinese Academy of Agricultural Sciences. Supernatant was collected from the feces suspension and inoculated intravenously into $40 \mathrm{SD}$ rats $(1 \mathrm{ml} / \mathrm{rat})$. Daily activities of the rats were monitored.SD rats were sacrificed at 14,21,35 and 70 days after infection (10 rats were sacrificed at each time-point). Sacrificed rats were divided into 4 groups (10 rats/group): Model group 1, model group 2, model group 3 and model group 4. SD rats in the control group $(n=10)$ were injected intravenously with $1 \mathrm{ml}$ of normal saline and were sacrificed after 1 week. Fresh blood was collected and the separated serum was stored at $-20^{\circ} \mathrm{C}$. Liver tissues were also collected and stored at $-20^{\circ} \mathrm{C}$. The level of HEV IgG antibody in serum was measured using double-antigen sandwich enzyme-linked immunosorbent assay (ELISA) (Kehua, Shanghai, China), and HEV mRNA expression level was measured in serum using fluorescence quantitative PCR method.

ORF3 protein expression. ORF3 protein expression level was measured using western blot analysis. The expression of ORF3 

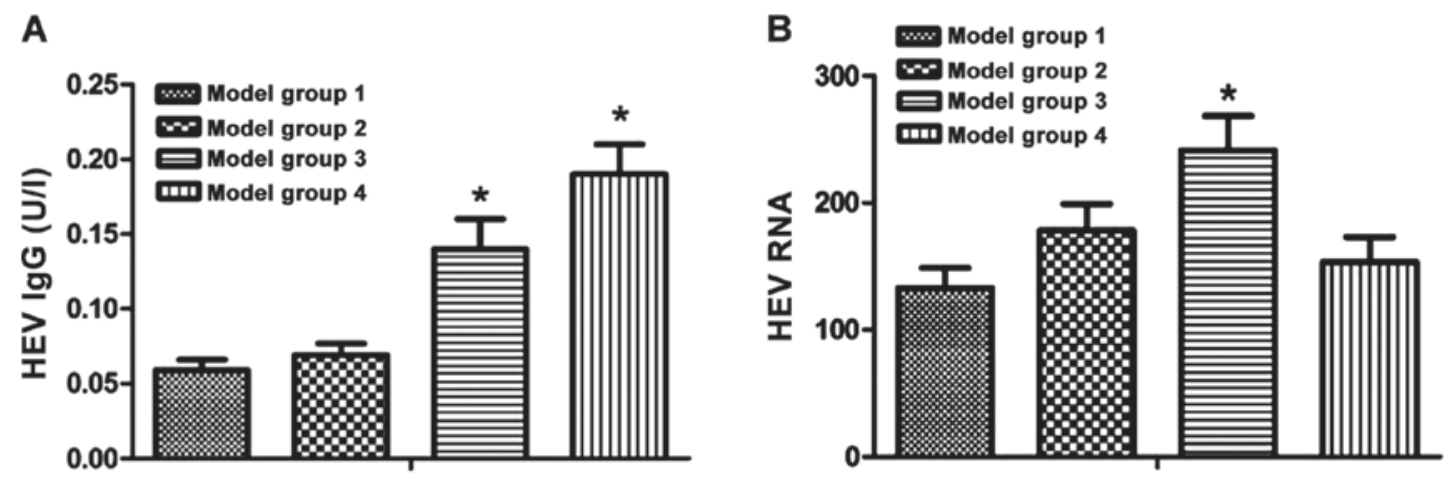

Figure 1. Comparison of expression levels of HEV IgG and HEV RNA in each model group. ${ }^{*} \mathrm{P}<0.05$.

protein in the control group was set as 100 , and the levels in each model group were calculated.

Detection of factors related to state of disease. Liver tissue homogenate was centrifuged and supernatant was collected, and adipocytokines levels were measured using ELISA. ELISA method was used to detect balance and immune outcomes of Th1/Th2 cells, levels of interferons (IFNs) and interleukin-4 (IL-4). Flow cytometry was used to determine $\mathrm{CD}^{+}$and $\mathrm{CD}^{+}{ }^{+} \mathrm{T}$ lymphocyte levels and calculate the $\mathrm{CD}^{+} / \mathrm{CD}^{+}$ratio.

Statistical analysis. SPSS 20.0 statistical software (SPSS, Inc., Chicago, IL, USA) was used for statistical analysis. Measurement data were expressed by mean \pm standard deviation (SD). Comparisons were analyzed by one-way analysis of variance (ANOVA) and comparisons between groups were evaluated by LSD method. Comparisons within groups were conducted using independent sample t-test, and Pearson's test was used for the correlation analysis after the normal test. $\mathrm{P}<0.05$ was considered to indicate a statistically significant difference.

\section{Results}

HEV IgG levels in the model group 3 and 4 were significantly higher than those of the model group 1 and 2. HEV RNA expression level in the model group 3 was significantly higher than that in other groups $(\mathrm{P}<0.05)$. Model group 3 was the most successful group in terms of HEV infection (Fig. 1). In the model group 3, ORF3 expression level in liver tissue was significantly higher than that of the control group, and the difference was statistically significant $(\mathrm{P}<0.05)$ (Fig. 2).

In the model group 3, fatty acid synthase (Fas) and tissue inhibitor of metalloproteinase (TIMP) levels in liver tissue were significantly higher than those in the control group, while angiotensin-converting enzyme inhibitor 2 (ACE-2) level was obviously lower than that of the control group. Differences were statistically significant $(\mathrm{P}<0.05)$ (Table I).

In the model group 3, IFNs, IL-4 and Th1/Th2 levels in the liver tissue were significantly higher than those in the control group. $\mathrm{CD}^{+} \mathrm{T}$ lymphocytes and the $\mathrm{CD}^{+} / \mathrm{CD}^{+}$ratio were lower than those of the control group. Differences were statistically significant $(\mathrm{P}<0.05)$ (Table II). Pearson's test concluded that ORF3 protein expression level in the model group 3 was

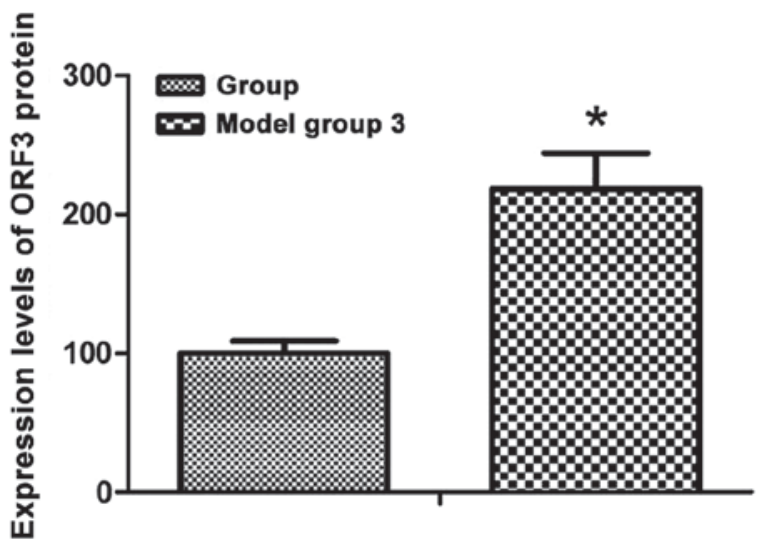

Figure 2. Comparison of expression levels of ORF3 protein in liver tissues of rats. ORF3, open reading frame 3 . ${ }^{*} \mathrm{P}<0.05$.

Table I. Adipocytokine levels in liver tissue.

\begin{tabular}{lccc}
\hline Groups & $\begin{array}{c}\text { Fas } \\
(\mathrm{mg} / \mathrm{ml})\end{array}$ & $\begin{array}{c}\text { TIMP-2 } \\
(\mu \mathrm{g} / \mathrm{l})\end{array}$ & $\begin{array}{c}\text { ACE-2 } \\
(\mathrm{ng} / \mathrm{ml})\end{array}$ \\
\hline Model group 3 & $34.28 \pm 4.19$ & $8.29 \pm 0.91$ & $0.23 \pm 0.04$ \\
Control group & $15.72 \pm 2.13$ & $3.76 \pm 0.45$ & $0.79 \pm 0.09$ \\
t-test & 5.723 & 5.293 & 5.382 \\
P-value & 0.012 & 0.017 & 0.014 \\
\hline
\end{tabular}

Fas, fatty acid synthase; TIMP, tissue inhibitor of metalloproteinase; ACE-2, angiotensin-converting enzyme inhibitor 2.

positively correlated with Fas, TIMP-2 and Th1/Th2 levels. It was negatively correlated with ACE- 2 and $\mathrm{CD} 4^{+} / \mathrm{CD} 8^{+}$levels $(\mathrm{P}<0.05)$ (Table III).

\section{Discussion}

Hepatitis $\mathrm{E}$ is a liver disease caused by a virus known as HEV. $\mathrm{HEV}$ infection can be serious in some cases and may lead to fulminant hepatic failure and death in a significant proportion of patients (5).

Early diagnosis of hepatitis E can significantly improve the prognosis. It has been reported that the three ORFs in HEV genome can be used for hepatitis $\mathrm{E}$ diagnosis. 
Table II. Th1/Th2 cells balance and immune outcome.

\begin{tabular}{|c|c|c|c|c|c|c|}
\hline \multirow[b]{2}{*}{ Groups } & \multicolumn{3}{|c|}{ Balance of Th1/Th2 } & \multicolumn{3}{|c|}{ Cellular immunity (\%) } \\
\hline & $\mathrm{IFN}-\gamma(\mathrm{ng} / \mathrm{l})$ & IL-4 (ng/l) & Th1/Th2 & $\mathrm{CD}^{+}+$ & $\mathrm{CD}^{+}$ & $\mathrm{CD}^{+} / \mathrm{CD}^{+}$ \\
\hline Model group 3 & $132.17 \pm 15.88$ & $67.62 \pm 7.13$ & $2.17 \pm 0.34$ & $45.72 \pm 5.15$ & $25.84 \pm 2.93$ & $1.51 \pm 0.17$ \\
\hline Control group & $89.63 \pm 9.42$ & $45.81 \pm 5.27$ & $1.58 \pm 0.18$ & $58.34 \pm 6.12$ & $21.28 \pm 2.76$ & $2.18 \pm 0.27$ \\
\hline t-test & 5.231 & 4.783 & 5.382 & 4.693 & 4.382 & 5.394 \\
\hline P-value & 0.014 & 0.021 & 0.012 & 0.024 & 0.031 & 0.010 \\
\hline
\end{tabular}

IFN- $\gamma$, interferon- $\gamma$; IL-4, interleukin-4.

Table III. ORF3 protein expression level.

\begin{tabular}{lcc}
\hline Indexes & $\begin{array}{c}\text { Coefficient of } \\
\text { determination } r\end{array}$ & P-value \\
\hline Fas & 0.393 & 0.021 \\
TIMP-2 & 0.312 & 0.027 \\
ACE-2 & -0.383 & 0.024 \\
Th1/Th2 & 0.339 & 0.026 \\
$\mathrm{CD}^{+} / \mathrm{CD}^{+}$ & -0.397 & 0.019
\end{tabular}

ORF3, open reading frame 3; Fas, fatty acid synthase; TIMP, tissue inhibitor of metalloproteinase; ACE-2, angiotensin-converting enzyme inhibitor 2.

ORF3 which is involved in virus pathogenicity (3), encodes a protein with more than four epitopes (6). Preliminary studies discovered that ORF3 protein may be involved in MAPK/ERK transduction signal pathway and could be related to hepatocyte apoptosis (7). ORF3 protein is expressed in early phase and can trigger cell proliferation and differentiation (8). Our results suggested that the expression level of ORF3 protein in the model group 3 was significantly higher than that of other groups. Higher level of ORF3 protein expression can be used as an index for disease diagnosis (9). Our results also revealed that Fas and TIMP levels in the liver tissue in the model group 3 were significantly higher than other groups, while ACE-2 level was relatively lower. It has been shown that adipocytokines are closely related to the occurrence of infection, inflammation and fibrosis (10). Results obtained from previous studies revealed an increased level of Fas expression in cells expressing ORF3 protein (11). Other studies reported an overexpression of TIMP in animal model with chronic liver disease (12). It has been shown that ACE-2 has an inhibitory effect on the release of pro-inflammatory factors as well as growth factors. Significant decline in ACE-2 expression has been reported in cells expressing ORF3 protein (13). It was suggested that ORF3 protein may be involved in the process of fibrosis in hepatic cells.

In acute hepatitis E, cytokines are involved in Th1/Th2 imbalance. Balance disorder of Th1/Th2 is an important internal mechanism in various diseases. Th1 type factors that can lead to tissue damage mainly include IL-1, IL-12 and IFN. Th2 type factors mainly include IL-4 and IL-10. Th2 cells mainly mediate humoral immunity and are involved in the secretion of anti-inflammatory factors.

Imbalance of Th1/Th2 in liver tissues is one of the important mechanisms in disease progression (14). A prior study (15) showed that HEV ORF3 protein in association with AMBP can suppress the proliferation as well as the migration of antigen induced $\mathrm{T}$ lymphocytes. It has been confirmed that cellular immunity plays an extremely important role in hepatitis A. Epidemiological and clinical characteristics of hepatitis $\mathrm{E}$ are very similar to those of hepatitis $\mathrm{A}$, therefore it can be speculated that inhibition of cellular immune function is also an important mechanism leading to occurrence and development of hepatitis E (16). We showed that in the model group 3, $\mathrm{CD}^{+}{ }^{+} \mathrm{T}$ lymphocytes and $\mathrm{CD} 4^{+} / \mathrm{CD}^{+}$ratio in the liver tissue were relatively low. $\mathrm{CD}^{+} / \mathrm{CD}^{+}$ratio directly reflects the state of cellular immune function. There is evidence showing that the cellular immune function suppression in hepatitis $\mathrm{E}$ may be related to the release of HEV particles, which is promoted by ORF3 protein (17).

Expression level of ORF3 is positively correlated with the level of Fas, TIMP-2 and Th1/Th2. It is negatively correlated with $\mathrm{ACE}-2$ level and $\mathrm{CD} 4^{+} / \mathrm{CD}^{+}$ratio. This suggested that ORF3 protein was directly involved in the occurrence and development of hepatitis E. We concluded that ORF3 expression level was directly related to severity and prognosis of hepatitis E. ORF3 protein can be considered as a sensitive and specific diagnostic index.

\section{Acknowledgements}

This study was supported by General Project on the basis of Applied Research in Yunnan Province (grant no. 2013FB060); Key Projects of Yunnan Provincial Department of Education (grant no. 2015Z161).

\section{References}

1. Li Z, Chen L and Liu Q: Activation of CXCL-8 transcription by hepatitis E virus ORF-1 via AP-1. Mediators Inflamm 2015: 495370, 2015.

2. Thiry D, Mauroy A, Pavio N, Purdy MA, Rose N, Thiry E and de Oliveira-Filho EF: Hepatitis E virus and related viruses in animals. Transbound Emerg Dis 64: 37-52, 2017.

3. Joshi SS and Arankalle VA: Differential immune responses in mice immunized with recombinant neutralizing epitope protein of hepatitis $\mathrm{E}$ virus formulated with liposome and alum adjuvants Viral Immunol 29: 350-360, 2016. 
4. Parvez MK: The hepatitis E virus ORF1 'X-domain' residues form a putative macrodomain protein/Appr-1"-pase catalytic-site, critical for viral RNA replication. Gene 566: 47-53, 2015.

5. Debing Y, Moradpour D, Neyts J and Gouttenoire J: Update on hepatitis E virology: implications for clinical practice. J Hepatol 65: 200-212, 2016.

6. Zhu YB, Huang YC and Tian DY: Analysis of genotype IV distribution of hepatitis $\mathrm{E}$ virus infections in Wuhan by sequencing the open reading frame 3 gene. Zhonghua Gan Zang Bing Za Zhi 20: 766-768, 2012 (In Chinese). http://europepmc.org/abstract/ $\mathrm{MED} / 23207338$.

7. Surjit M, Oberoi R, Kumar R and Lal SK: Enhanced alpha1 microglobulin secretion from hepatitis E virus ORF3-expressing human hepatoma cells is mediated by the tumor susceptibility gene 101. J Biol Chem 281: 8135-8142, 2006.

8. Tyagi S, Surjit M and Lal SK: The 41-amino-acid C-terminal region of the hepatitis E virus ORF3 protein interacts with bikunin, a kunitz-type serine protease inhibitor. J Virol 79: 12081-12087, 2005.

9. Wang H, Ji F, Liang H, Gu H, Ning Z, Liu R and Zhang G: A proline-rich domain in the genotype 4 hepatitis E virus ORF3 $\mathrm{C}$-terminus is crucial for downstream $\mathrm{V}^{105} \mathrm{DLP}^{108}$ immunoactivity. PLoS One 10: e0133282, 2015.

10. Dong C, Zafrullah M, Mixson-Hayden T, Dai X, Liang J, Meng $\mathrm{J}$ and Kamili S: Suppression of interferon- $\alpha$ signaling by hepatitis E virus. Hepatology 55: 1324-1332, 2012.

11. Li L, Pilo GM, Li X, Cigliano A, Latte G, Che L, Joseph C, Mela M, Wang $\mathrm{C}$, Jiang $\mathrm{L}$, et al: Inactivation of fatty acid synthase impairs hepatocarcinogenesis driven by AKT in mice and humans. J Hepatol 64: 333-341, 2016.
12. Latronico T, Mascia C, Pati I, Zuccala P, Mengoni F, Marocco R, Tieghi T, Belvisi V, Lichtner M, Vullo V, et al: Liver fibrosis in $\mathrm{HCV}$ monoinfected and HIV/HCV coinfected patients: dysregulation of matrix metalloproteinases (MMPs) and their tissue inhibitors TIMPs and effect of HCV protease inhibitors. Int J Mol Sci 17: 455, 2016.

13. Lubel JS, Herath CB, Tchongue J, Grace J, Jia Z, Spencer K, Casley D, Crowley P, Sievert W, Burrell LM, et al: Angiotensin-(1-7), an alternative metabolite of the renin-angiotensin system, is up-regulated in human liver disease and has antifibrotic activity in the bile-duct-ligated rat. Clin Sci (Lond) 117: 375-386, 2009.

14. Husain MM, Aggarwal R, Kumar D, Jameel S and Naik S: Effector T cells immune reactivity among patients with acute hepatitis E. J Viral Hepat 18: e603-e608, 2011.

15. Tyagi S, Surjit M, Roy AK, Jameel S and Lal SK: The ORF3 protein of hepatitis $\mathrm{E}$ virus interacts with liver-specific alpha1-microglobulin and its precursor alpha1-microglobulin/bikunin precursor (AMBP) and expedites their export from the hepatocyte. J Biol Chem 279: 29308-29319, 2004.

16. Gisa A, Suneetha PV, Behrendt P, Pischke S, Bremer B, Falk CS, Manns MP, Cornberg M, Wedemeyer H and Kraft AR: Cross-genotype-specific T-cell responses in acute hepatitis $\mathrm{E}$ virus (HEV) infection. J Viral Hepat 23: 305-315, 2016.

17. Paingankar MS and Arankalle VA: Identification and characterization of cellular proteins interacting with hepatitis E virus untranslated regions. Virus Res 208: 98-109, 2015. 